\title{
Investigation of Mechanical Properties on Fibre Reinforced Polymer Nanocomposites Using ABAQUS
}

\author{
A. Padma Rao ${ }^{1 *}, V$. Murali Krishna ${ }^{2}$, and Ganji $\mathrm{Venu}^{3}$ \\ ${ }^{1}$ Department of Mechanical Engineering, B. V. Raju Institute of Technology, Narsapur, Telangana 502313, India \\ ${ }^{2,3}$ Department of Mechanical Engineering, B. V. Raju Institute of Technology, Narsapur, Telangana 502313, India
}

\begin{abstract}
The main aim of this work is to explore the Nanocomposites for industrial and engineering applications. Nanocomposites or nanofillers are bringing exemplary changes in the field of material science and polymer composites. In this complicated process a minor part of material is added to a variety of polymers and other materials which can improve the performance and quality of materials including mechanical, thermal, flexural stiffness, tensile strength, toughness, water absorption, flame retardancy and scratch resistance etc. This paper is concerned with investigation of the mechanical properties on composite material made of E-Glass fibre and LY556 epoxy with induced nanoparticles under tensile load. The tensile tests carried out on different composite samples as per the ASTM standard.
\end{abstract}

\section{Introduction}

A composite material consists of two or more materials whose combination produces improved properties that are different from those of its constituents. Composites can be very important because of its strong, stiff and very light in weight. So, ratios of strength to weight and stiffness to weight are several times stronger than steel or aluminum. Also, possible to achieve combinations of properties not attainable with metals, ceramics or polymers alone. In the recent years, natural fibre reinforced composites are treated as most promising material in different applications due to its attractive properties.

The unavoidable use of E-glass fibre reinforced epoxy composites in many applications makes them a particulate reinforced polymer matrix composite that has different properties, both in size and in percentage of e-glass fibre and epoxy composites. This requires knowing which composition is the most appropriate for the various applications. The utilization of composite structures is getting progressively significant and their work can be used for lightweight and complex structures. Different sorts of composite materials have been presented and concentrated in different scales from full scale to nano composites. Considering long mixes fortified with various kinds of filaments alongside nano fillers.

Most preferred composites are polymer matrix composites along with some of the nano particles. The materials like
E-Glass fibre, Epoxy LY556, Hardner (HY951), Silicon mould release spray, Teflon sheet, Mould, Graphene Oxide nanoparticles, Silicon Di-oxide nanoparticles are used to prepare the polymer nano composites with different compositions of nanofillers induced into epoxy to investigate the tensile behavior of the composite material.

E- Glass fiber is a light weight woven composite material that is commonly used in industrial, marine and aerospace applications. It is most suitable for industry standard and provides an excellent balance between cost and performance. High strength glass fibre composites are compared by physical, mechanical, electrical, thermal, acoustical, optical and radiation properties.

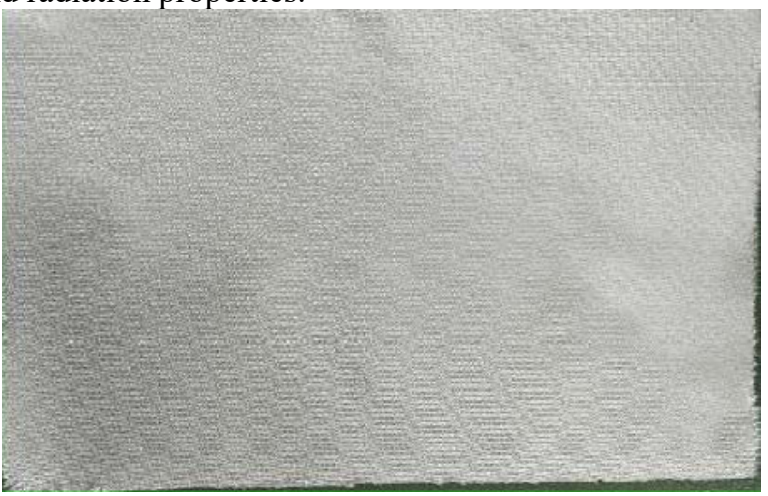

Fig.1. E-glass Fibre

Epoxy pitches have a settled record in a wide scope of composite parts, structures and solid fix. The structure of 
the gum can be designed to yield various items with changing degrees of execution. A significant advantage of epoxy saps over unsaturated polyester gums is their lower shrinkage. Epoxy pitches can likewise be defined with various materials or mixed with other epoxy tars to accomplish explicit execution highlights. Epoxies are utilized essentially for manufacturing elite composites with prevalent mechanical properties, protection from destructive fluids and conditions, predominant electrical properties, great execution at raised temperatures, great grip to a substrate, or a mix of these advantages. Epoxy tars don't be that as it may, have especially great UV obstruction.

Hardener is a substance blended in with polymer resin or other defensive covering to make the completion harder or increasingly sturdy. It is a restoring operator for epoxies or fiberglass. A specialist which doesn't go into the response is known as a reactant hardener or impetus. Hardener is generally classed as a destructive, and as an aggravation when in contact with the skin or by inward breath. The epoxy and hardener are blended in the proportion of 10:1 by weight.

Graphene oxide nanoparticles are utilized to improve the mechanical properties. By adding the graphene oxide nanoparticles to the composites in modest quantity can improve the mechanical properties of the composites in an enormous degree. The mechanical properties like quality, hardness, strength and so on improves with a high quality.

Silicon dioxide $\left(\mathrm{SiO}_{2}\right)$ is a natural compound made of two of the earth's most abundant materials: silicon ( $\mathrm{Si}$ ) and oxygen $\left(\mathrm{O}_{2}\right)$. Silicon dioxide is most often recognized in the form of quartz. It's found naturally in water, plants and animals. The earth's crust is 59 percent silica.

Polymer lattice composites are favored for assembling of parts of aviation and different applications as a result of their capacity of being light without trading off to their durability and quality. These are so light weight that they are around one fifth of the heaviness of prepares of certain evaluations and furthermore sturdier to multiple times of certain evaluations of prepares. Polymer network composites have explicit rewards and cutoff points similarly as with all building materials. The quick development in innovations and requirement for assortment of materials has been the key for the extension of composites having improved mechanical, temperature and artificially resistive properties while contrasted with the customary building materials. We get the particular solidness or quality of a material when it is isolating by the material thickness. The particular properties of PMCs are generally excellent that they permit planning basic segments of superior. They additionally give directional properties to support which is fit for protection from the stacking of a structure on a given segment. Hybrid nano polymer composites exhibits better mechanical properties depending upon the ratio of nanoparticle mixture induced into polymer matrix.

\section{Literature Review}

Jun Feng Hu et al. [1] conducted an experimental test to determine the crack healing performance using si3n $4 /$ sic ceramic composite. Pre-cracks with different lengths were introduced on the tensile side of specimens by Vickers hardness tester. Subsequent to heat treatment at $1300^{\circ} \mathrm{C}$, it is able to completely heal a crack of $200 \mu \mathrm{m}$, thereby achieving a substantial strength recovery for pre- cracked specimens even with much longer cracks $(1200 \mu \mathrm{m})$ after heat treatment of the optimal heating temperature of $1300^{\circ} \mathrm{C}$. crack closure and strength recovery of the pre-cracked specimen is considered to be triggered by the creation of $\mathrm{SiO}_{2}$, liquid aluminosilicate and silicon yitrium oxide by the oxidation reaction as filling mechanism during heat treatment. G. L. Devnani et al. [2] studied effect of nanofillers on the properties of natural fiber reinforced polymer composites. The outcome of this review indicates that the mechanical properties of natural fiber reinforced polymer composites improve significantly by the use of nanofillers. The water absorption of these composites also reduces in many of the studies, so the use of nanofillers can be an important aspect in this field but an optimum concentration or loading is very important to keep a balance of properties and at the same time an economic consideration is also very important for the use of these novel materials. Pavan Kumar Gangineni et al. [3] focused on the enhancement of bending properties of CFRP composites also made the fractographic analysis using SEM to know the failure of micro-mechanism. Ramu P et al. [4] explained the enhancement in the mechanical properties of FRP composite and its applications. Andrew Makeev et al. [5] demonstrated the compressive strength of the hybrid HM composite fibre. Ramesh Kumar Nayak et al. [6] from their work on the Influence of seawater absorption on retention of mechanical properties of nano - $\mathrm{TiO}_{2}$ embedded glass fiber reinforced epoxy polymer matrix composites the effect of nano - $\mathrm{TiO}_{2}$ content and seawater aging, on mechanical properties of neat epoxy and nanocomposites, were evaluated and reported. The seawater diffusivity of the nanocomposite containing $0.1 \mathrm{wt} \%$ of nano - $\mathrm{TiO}_{2}$ reduced by $15 \%$ as compared to neat epoxy/control GFRP composite. The flexural strength of the nanocomposite containing $0.1 \mathrm{wt} \%$ of nano $-\mathrm{TiO}_{2}$ improved by $11 \%$ in dry condition and $15 \%$ in seawater aged condition. Shibo Li et al. [7] from their work healing cracks through an oxidative healing mechanism at high temperature in oxidizing environments with the recovery of original performance and functionality. However, the oxidation induced repair may be impossible when the ceramics are used in vacuum or inert atmospheres. In this paper the author reported on the crack healing of a ti2snc are completely filled by only metallic sn at 
temperature above $800^{\circ} \mathrm{C}$ for only $1 \mathrm{~h}$ in vacuum. K. $\mathbf{P}$. Ashik et al. [8] made the review on the mechanical properties of natural fibers like sisal, bamboo, jute etc. Joao R. Correia et al. [9] studied (i) characterizing the variation of tensile, shear and compressive properties of GFRP pultruded material from ambient temperature up to $250^{\circ} \mathrm{C}$, and (ii) assessing the accuracy of different strength prediction methods suggested in the literature. The following main conclusions are drawn:1. Experimental data reported herein confirmed that in the range of temperatures analyzed, which includes the glass transition process of the polymeric matrix, the GFRP material is much more vulnerable under shear and compression than under tension. 2. Tensile strength is considerably reduced when the GFRP pultruded material is exposed to elevated temperature, but at $220^{\circ} \mathrm{C}$ the material still retains about $54 \%$ of its ambient temperature strength. 3. Shear and compressive strengths were drastically reduced for elevated temperatures, exhibiting strength retentions compared to ambient temperature of only $11 \%$ and $5 \%$, respectively. 4. All descriptive models analyzed were able to simulate the pattern of variation of tensile, shear and compressive strengths as a function of temperature, providing reasonably accurate estimates of experimental strength data. Strength estimates obtained from the phenomenological model proposed by Bai and Keller were less accurate and, for some temperature ranges and types of loading they were non conservative. V. Muthukumar et al. [10] made the investigation of comparison of mechanical properties of kenaf, jute, sisal fiber reinforced with different hybrid composites. Haider AL et al. [11] made the experimental investigation on mechanical properties of one direction normal modulus CFRP. Stephan Sprenger et al. [12] made the improvement in mechanical properties of fiber reinforced composites. A. Padma Rao et al. [13], caompared the nanocomposite material with and without $\mathrm{SiO}_{2}$. B. Mouhmida et al. [14] studied and analyzed the PA66 Glass Fiber Reinforced Polymer by using Scanning Electron Microscope. R.O. Ochola et al. [15] compared the flexural and tensile properties of glass fiber reinforced polymer and carbon fiber reinforced polymer.

\section{Specimen preparation}

Materials like E-glass fibre, Epoxy (LY556), Hardener (HY951), Graphene oxide nanoparticles, Silicon dioxide nanoparticles are used as shown in the Fig. 2. Glass Fiber Reinforced Epoxy Composites (GFRP) was made by hand lay-up methods. The fortifying material that is the Eglass fiber was laid. Subsequently interchange layers were opposite to one another. This course of action improves the quality of the composite every way. Eighteen interchange layers of glass strands organized thusly alongside epoxy lattice in the middle of each layer to get thickness of $3 \mathrm{~mm}$. Fiber is kept up at $60 \%$ by weight.
- To prepare the test specimen cut the E Glass fiber as per required measurements according to ASTM gauges.

- Then take the necessary measure of Resin and Hardener. The necessary extents to blend the Resin and Hardener ought to be 10:1 and furthermore accept the nano particles according to the counts.

- The specimens are set up with the assistance of wooden shape. The Teflon sheet showered with silicon discharge splash is utilized for simple expulsion of specimen from the mould.

- In the measuring utensil the necessary measure of pitch is taken and the necessary measure of nano particles are likewise added to it and kept in ice shower for sonication in Ultra Sonicator Processor for appropriate blending of nano particles in sap.

After sonication the necessary sum hardener is blended to it. And afterward by hand layup process, the E glass fiber and the blend of tar, nano particles and hardener is applied to wooden mould form. The restoring begins following 20 minutes due the concoction response and the specimen are totally relieved for 6 to 8 hours.

- After expelling the specimens, they have to send for the machining procedure to slice the specimen as per the measurement.

- After the machining procedure the specimens with required measurements are utilized to perform tensile tests.

- While setting up the test specimen, the nano particles $\left(\mathrm{SiO}_{2}-\mathrm{GO}\right)$ ought to be blended well by Using Ultra Sonicator Processor. To do this procedure the blend of sap and nano particles are kept in ice shower. Ice used to cool the blend during sonication process and the glass receptacle ought to be put inside the Sonicator and press the beginning catch. The sonication ought to be rehashed for each 6-10 minutes at 4 stretches. 


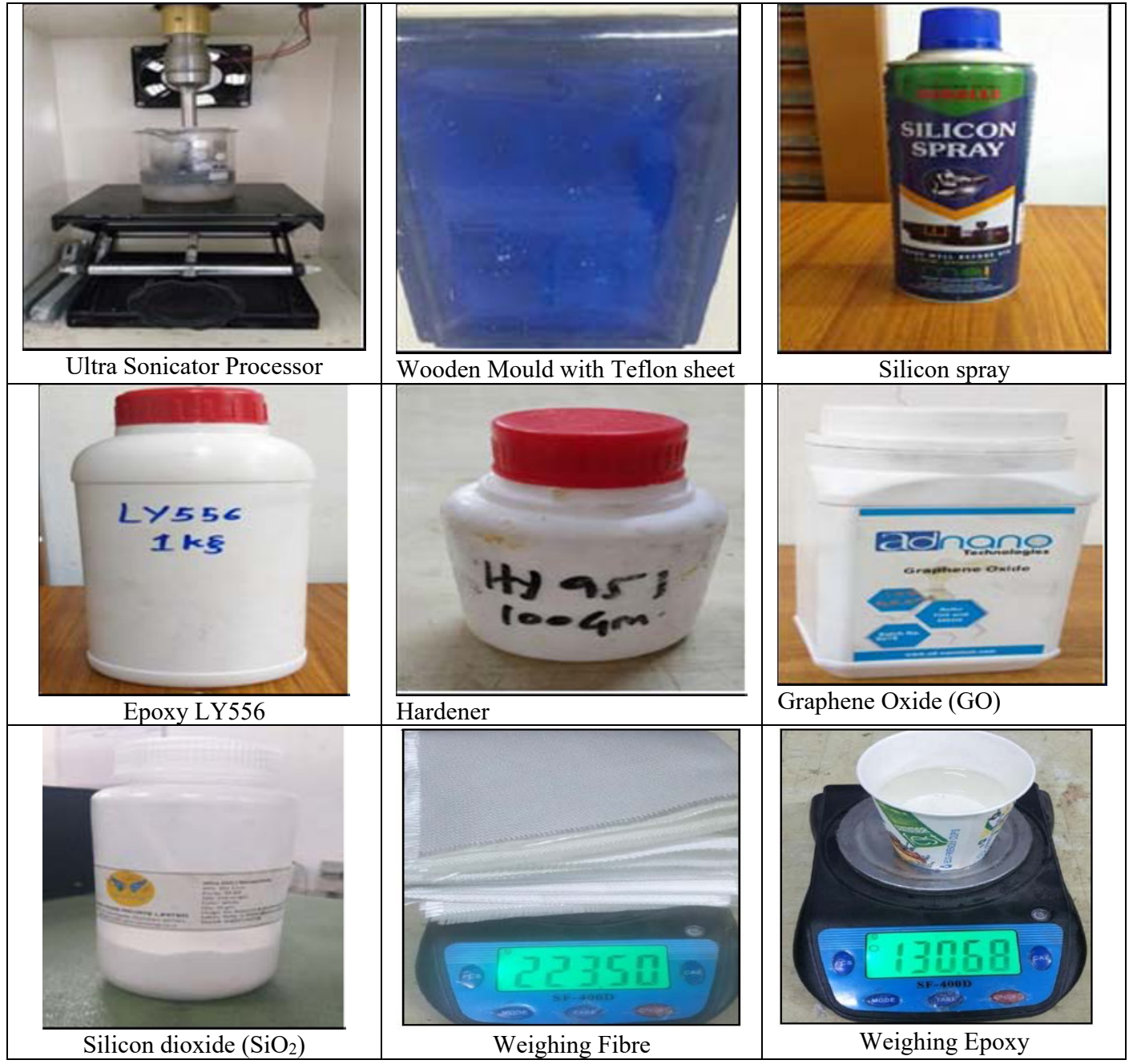

Fig.2. Material for the preparation of specimen

Table 1. Values at different percentages of $\mathrm{SiO}_{2}-\mathrm{GO}$

\begin{tabular}{|l|l|l|l|l|l|}
\hline Percentage & $\mathbf{S i O}_{2} \%-\mathbf{G O} \%$ & $\begin{array}{l}\text { Weight of } \\
\mathrm{Si0} \mathbf{2}_{2}\end{array}$ & $\begin{array}{l}\text { Weight of } \\
\text { GO }\end{array}$ & $\begin{array}{l}\text { Weight of } \\
\text { resin }\end{array}$ & $\begin{array}{l}\text { Weight of } \\
\text { hardener }\end{array}$ \\
\hline $0.5 \%$ & $0.3 \%-0.2 \%$ & 0.04633 & 0.02387 & 12.41 & 1.241 \\
\hline $1 \%$ & $0.6 \%-0.4 \%$ & 0.0926 & 0.0477 & 12.38 & 1.237 \\
\hline $1.5 \%$ & $0.9 \%-0.6 \%$ & 0.13893 & 0.04161 & 12.34 & 1.23 \\
\hline $2 \%$ & $1.2 \%-0.8 \%$ & 0.18535 & 0.0954 & 12.31 & 1.231 \\
\hline $2.5 \%$ & $1.5 \%-1 \%$ & 0.2316 & 0.1193 & 12.28 & 1.22 \\
\hline $3 \%$ & $1.8 \%-1.2 \%$ & 0.2779 & 0.1432 & 12.25 & 1.21 \\
\hline
\end{tabular}




\section{Test specimens:}

The specimens to be tested are prepared at different percentage of $\mathrm{SiO}_{2}-\mathrm{GO}$ are shown in Fig. 3 .

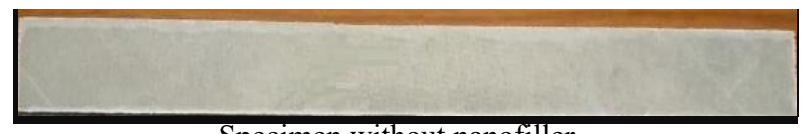

Specimen without nanofiller

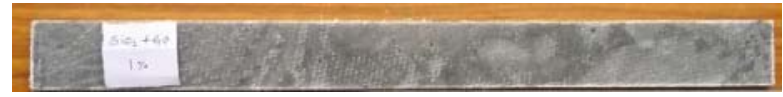

Specimen with $1 \%$ of $\mathrm{SiO}_{2}-\mathrm{GO}$

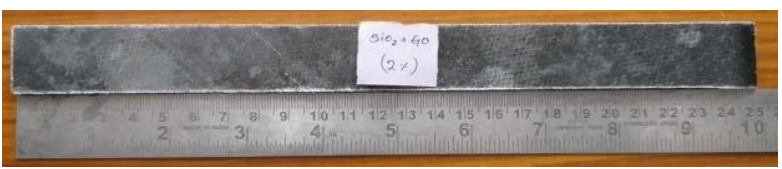

Specimen with $2 \%$ of $\mathrm{SiO}_{2}-\mathrm{GO}$

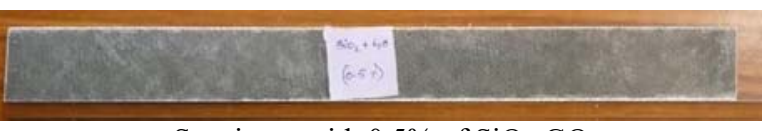

Specimen with $0.5 \%$ of $\mathrm{SiO}_{2}-\mathrm{GO}$

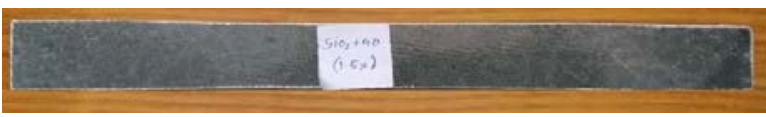

Specimen with $1.5 \%$ of $\mathrm{SiO}_{2}-\mathrm{GO}$

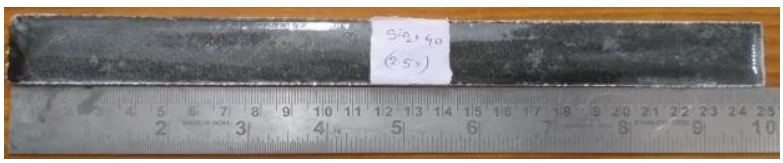

Specimen with $2.5 \%$ of $\mathrm{SiO}_{2}-\mathrm{GO}$

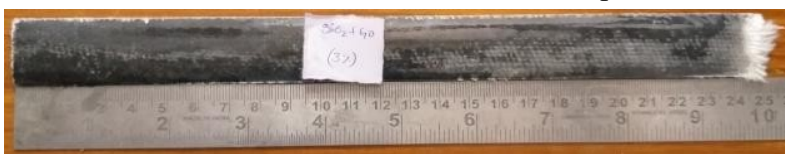

Specimen with $3 \%$ of $\mathrm{SiO}_{2}-\mathrm{GO}$

Fig.3 Different specimen for testing

The test specimen models prepared in CATIA are shown in Fig. 4.

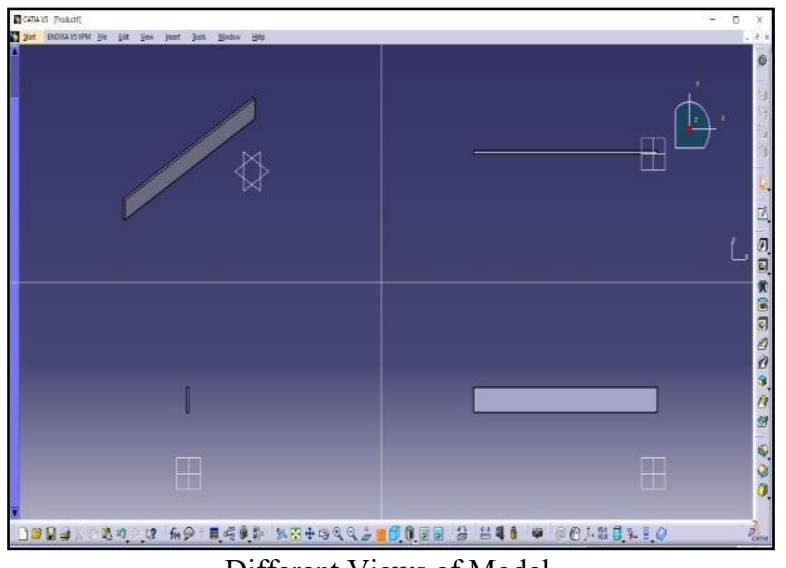

Different Views of Model

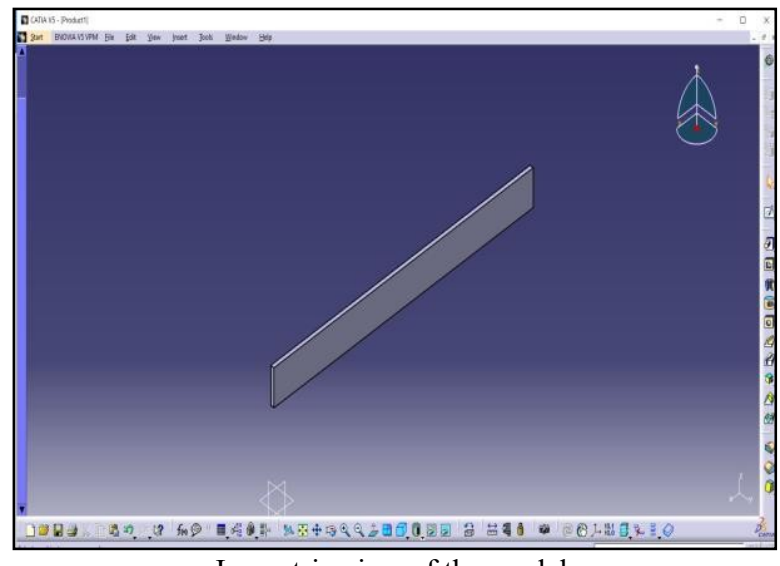

Isometric view of the model

Fig.4 Test specimen models 


\section{Experimental Work}

The prepared test specimen with at different percentages of Nano Particles and without Nano Particles will undergoes tensile testing.

Table 2. Specimen Dimensions

\begin{tabular}{|l|l|l|l|}
\hline $\begin{array}{l}\text { S. } \\
\text { No. }\end{array}$ & TEST & $\begin{array}{l}\text { ASTM } \\
\text { STANDARDS }\end{array}$ & $\begin{array}{l}\text { SPECIMEN } \\
\text { DIMENSION(MM) }\end{array}$ \\
\hline 1 & Tensile & ASTM D3039 & $250 \times 25 \times 3$ \\
\hline
\end{tabular}

\subsection{Tensile Test}

Elastic test also called as pressure test is one of the most essential and regular kinds of mechanical testing. This test applies pulling power to a material and measures the specimen reaction to the pressure. By doing this, pliable tests decide the strength of the material and the amount it can stretch. After conducting the test one can acquire a total profile of its elastic properties.

\subsection{Test Procedure}

- The tensile test is performed on Universal Testing machine (UTM).

- At first, set the heap pointer to zero and afterward the readied sample with required measurements is connected among upper and center cross leaders of the machine.

- Now start the machine and apply the load to the sample at a moderate rate utilize the heap and empty hand wheels. Note down the perusing of all through the procedure when the specimen is stacked bit by bit. Continue stacking up till the specimen break and record the readings.

- Measure and record the breadth of the specimen at the break point and set up the information sheet.

- Tensile quality changes starting with one material then onto the next material relying upon the mechanical properties

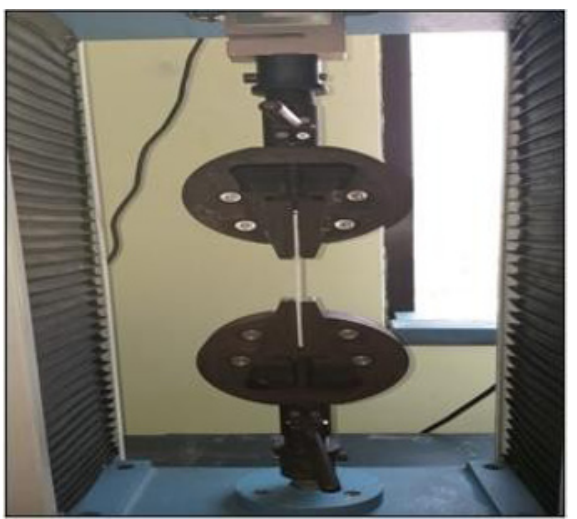

Fig.5 Specimen in Tensile Testing Machine

\section{Results And Discussion}

\subsection{Tensile test result for specimens}

The specimens after tensile testing are shown in Fig. 6 below.

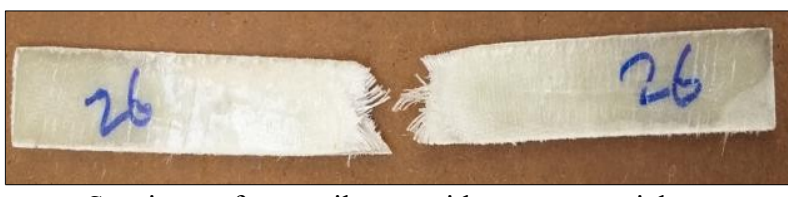

Specimen after tensile test without nanoparticles

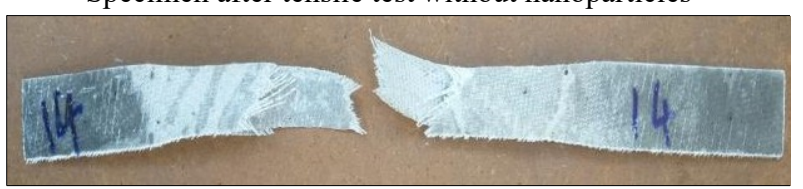

Specimen after tensile test with $1 \% \mathrm{SiO}_{2}-\mathrm{GO}$

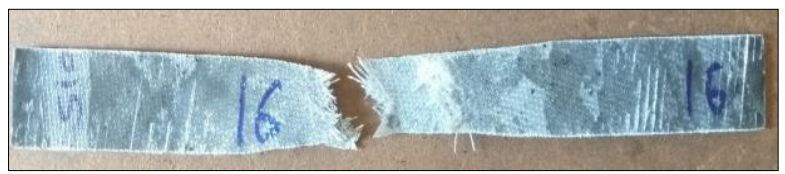

Specimen after tensile test with $2 \% \mathrm{SiO}_{2}-\mathrm{GO}$

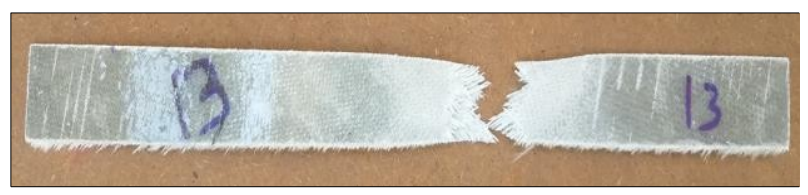

Specimen after tensile test with $0.5 \% \mathrm{SiO}_{2}-\mathrm{GO}$

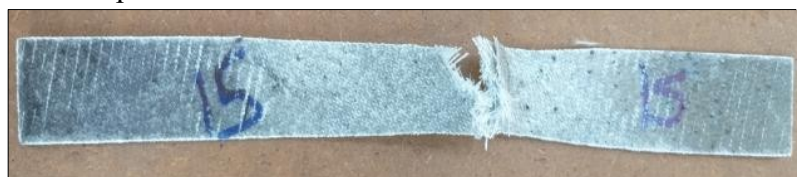

Specimen after tensile test with $1.5 \% \mathrm{SiO}_{2}-\mathrm{GO}$

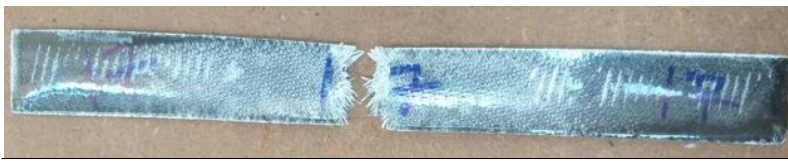

Specimen after tensile test with $2.5 \% \mathrm{SiO}_{2}-\mathrm{GO}$

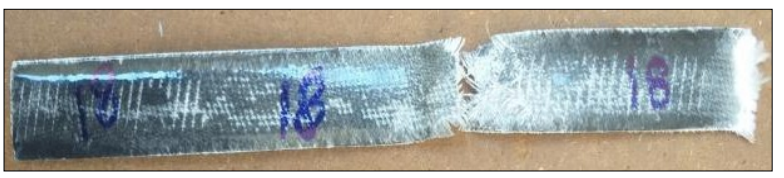

Specimen after tensile test with $3 \% \mathrm{SiO}_{2}-\mathrm{GO}$

Fig.6 Tested specimen at different percentages of $\mathrm{SiO}_{2}-\mathrm{GO}$ 
The experimental results are obtained. They are the tensile strength, elongation and modulus of elasticity Table 3. Tensile test results for specimen

\begin{tabular}{|c|c|c|c|c|c|c|}
\hline $\begin{array}{c}\text { S. } \\
\text { No. }\end{array}$ & Specimen type & $\begin{array}{c}\text { Cross sectional } \\
\text { area(mm }\end{array}$ & $\begin{array}{c}\text { Maximum } \\
\text { load (N) }\end{array}$ & $\begin{array}{c}\text { Maximum } \\
\text { elongation } \\
\text { (mm) }\end{array}$ & $\begin{array}{c}\text { Maximum } \\
\text { tensile } \\
\text { strength } \\
\text { (MPa) }\end{array}$ & $\begin{array}{c}\text { Tensile } \\
\text { modulus of } \\
\text { elasticity } \\
\text { (G Pa) }\end{array}$ \\
\hline 1 & $\begin{array}{c}\text { Specimen without } \\
\text { nanoparticle }\end{array}$ & 83 & 6898 & 14 & 98 & 0.89 \\
\hline 2 & $\mathrm{SiO}_{2}-\mathrm{GO}(0.5 \%)$ & 75 & 7189.2 & 14.98 & 100.08 & 1.1228 \\
\hline 3 & $\mathrm{SiO}_{2}-\mathrm{GO}(1 \%)$ & 75 & 6223.7 & 25.27 & 83.6 & 1.23 \\
\hline 4 & $\mathrm{SiO}_{2}-\mathrm{GO}(1.5 \%)$ & 75 & 7620.5 & 27.41 & 97.94 & 1.2061 \\
\hline 5 & $\mathrm{SiO}_{2}-\mathrm{GO}(2 \%)$ & 75 & 7350.5 & 16.5 & 90.74 & 1.2902 \\
\hline 6 & $\mathrm{SiO}_{2}-\mathrm{GO}(2.5 \%)$ & 75 & 9100.1 & 16.18 & 117.94 & 1.4278 \\
\hline 7 & $\mathrm{SiO}_{2}-\mathrm{GO}(3 \%)$ & 75 & 8564 & 15.3 & 102.37 & 1.3653 \\
\hline
\end{tabular}

Graph: The graph plotted between the Young's modulus and percentage of nano particle

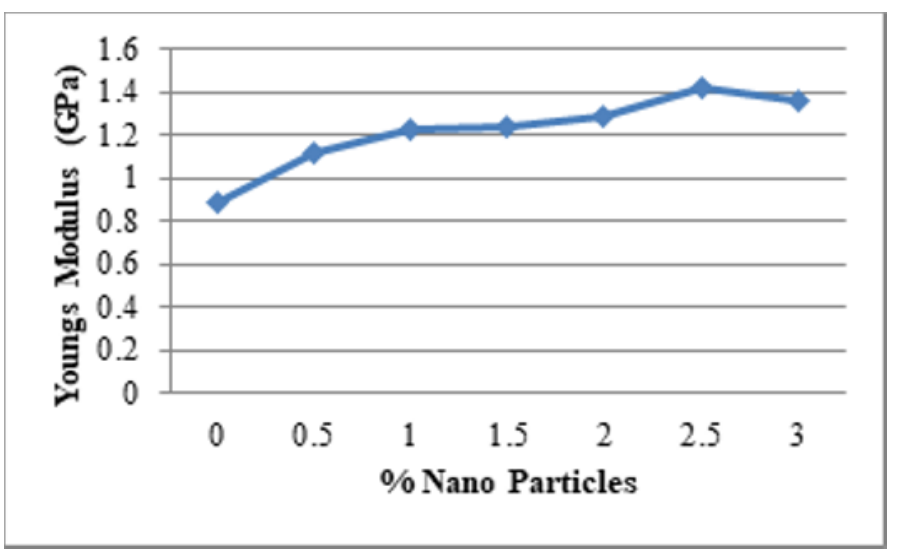




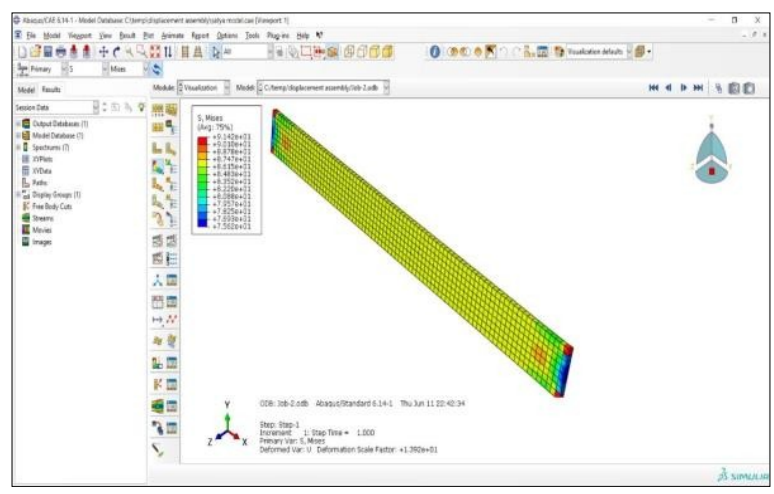

Stresses in composite with $0.5 \%$ nanoparticle

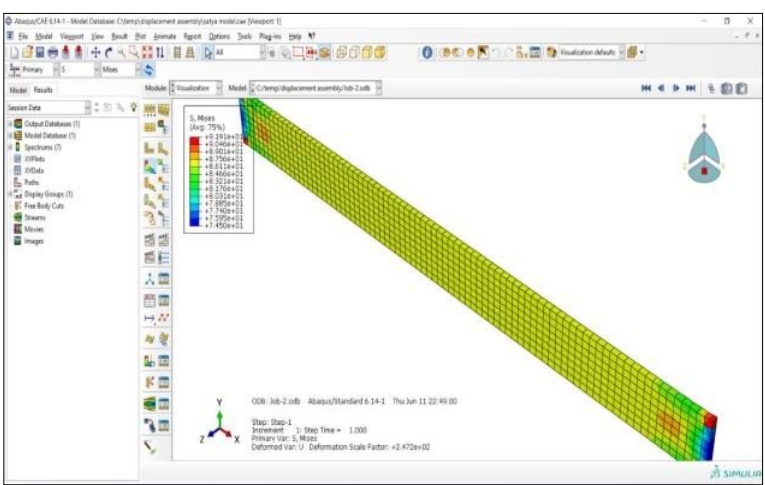

Stresses in composite with $1 \%$ nanoparticle

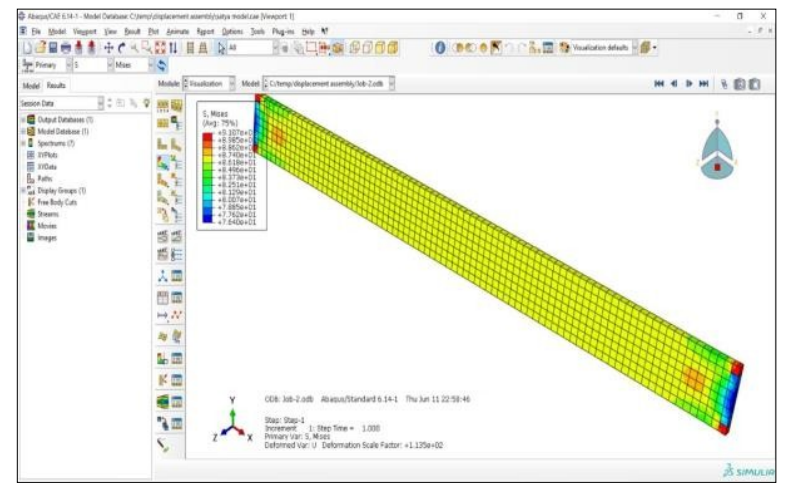

Stresses in composite with $1.5 \%$ nanoparticle

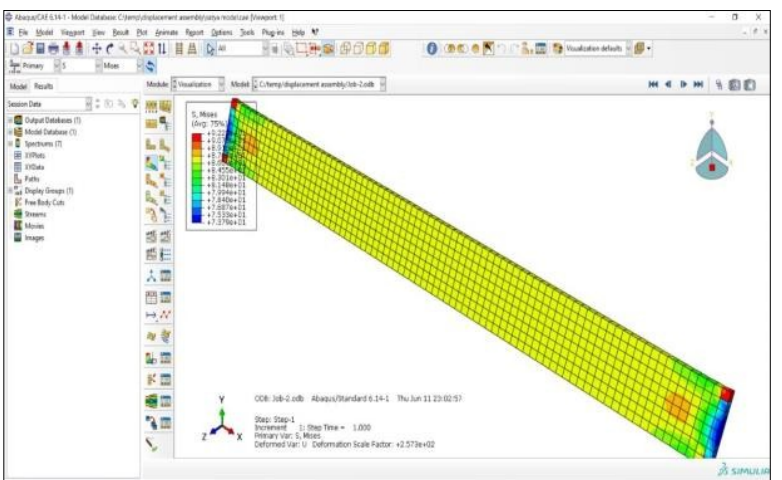

Stresses in composite with $2 \%$ nanoparticle

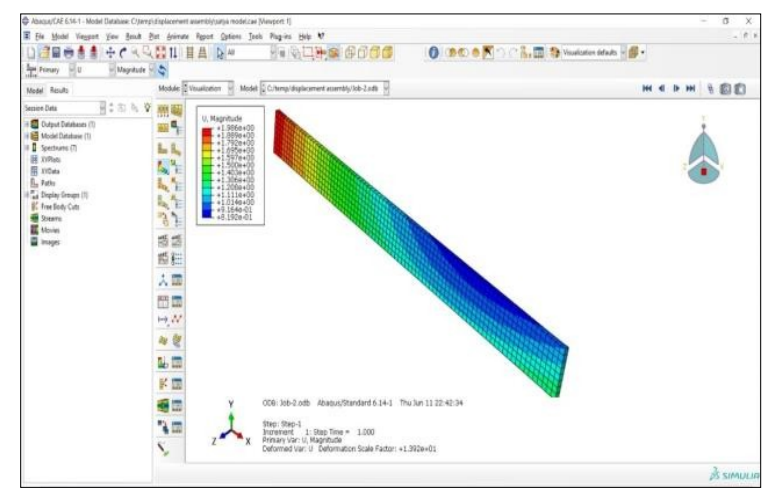

Deformation in composite with $0.5 \%$ nanoparticle

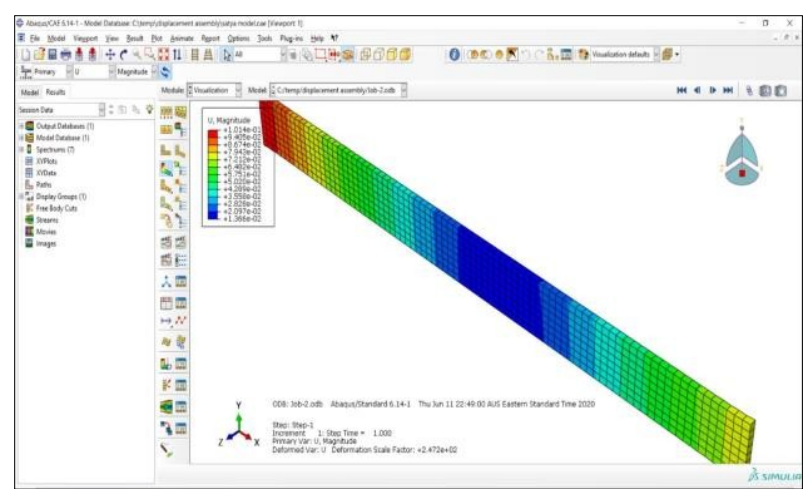

Deformation in composite with $1 \%$ nanoparticle

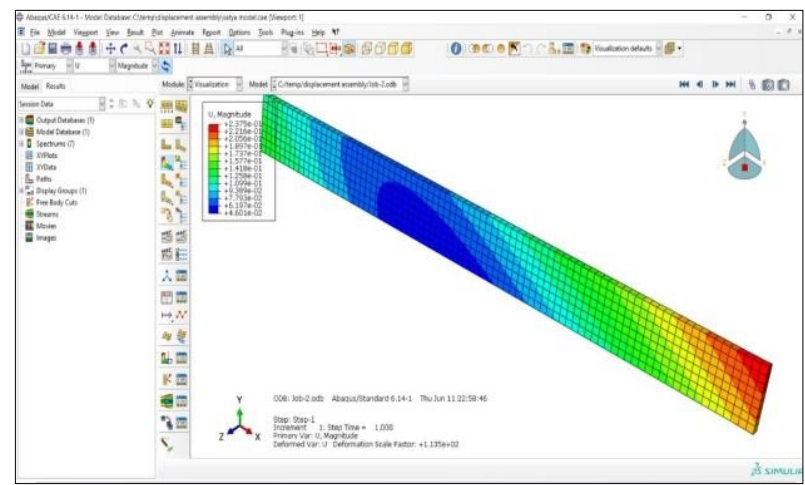

Deformation in composite with $1.5 \%$ nanoparticle

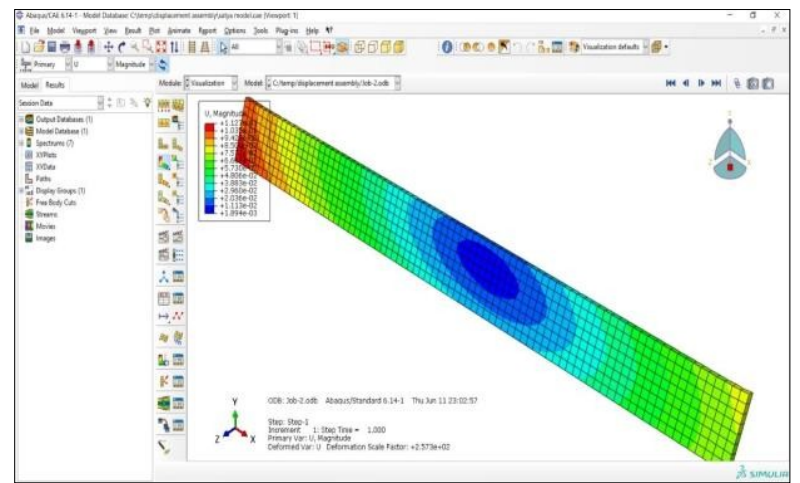

Deformation in composite with $2 \%$ nanoparticle 


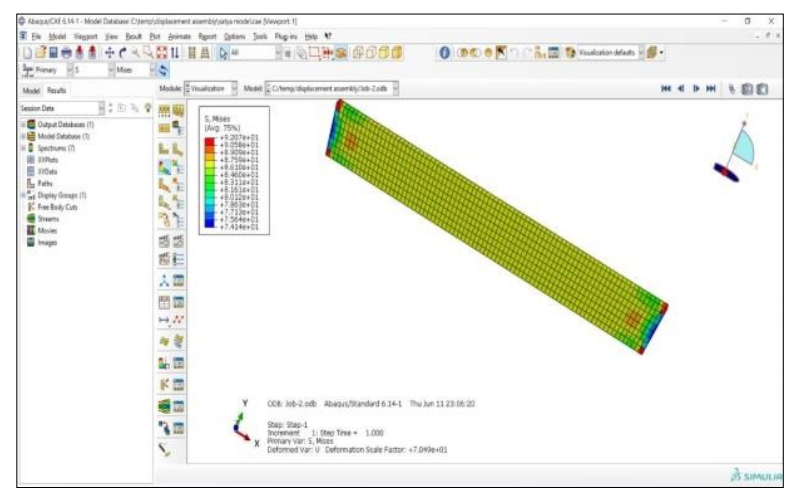

Stresses in composite with $2.5 \%$ nanoparticle

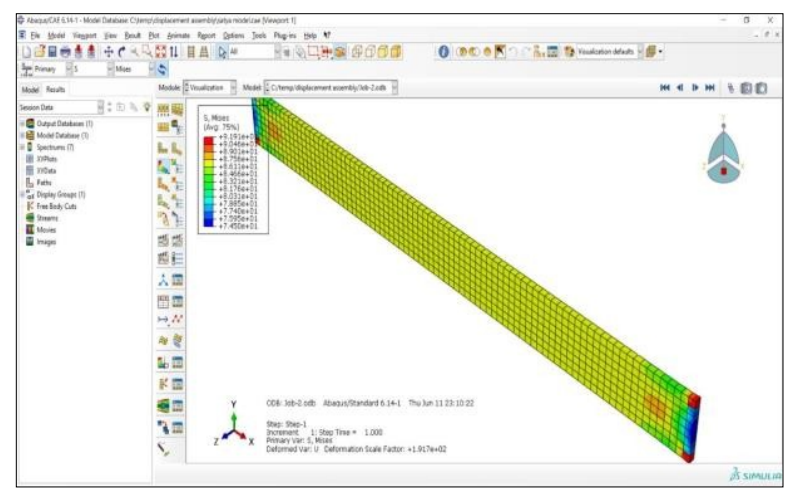

Stresses in composite with 3\% nanoparticle

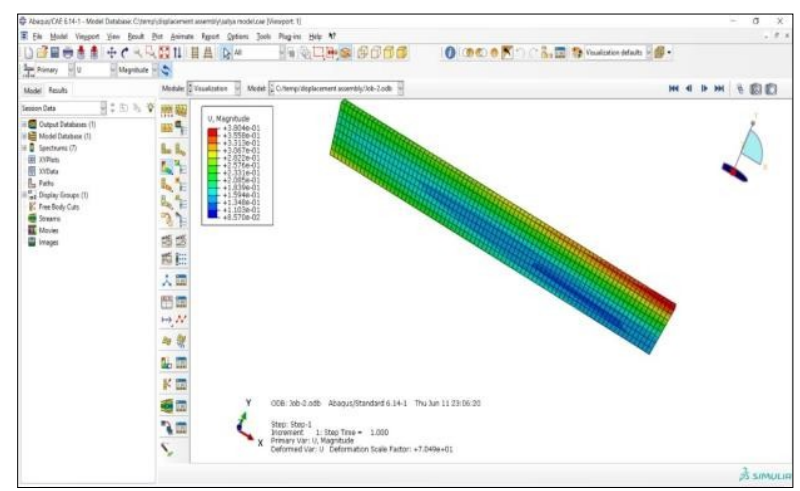

Deformation in composite with $2.5 \%$ nanoparticle

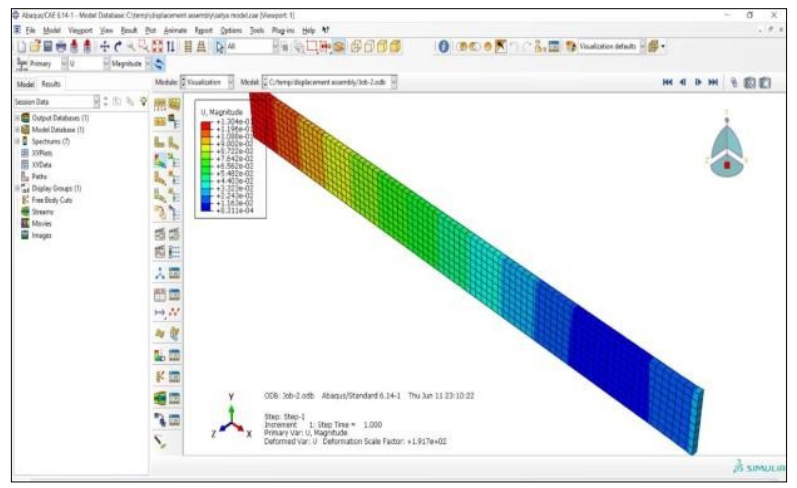

Deformation in composite with 3\% nanoparticle

Fig.7 The results obtained from the ABAQUS software

\section{Conclusions}

The analyses have been arranged according to ASTM gauges to set up the distinctive composite specimen for contemplating the mechanical and physical behavior of polymer composites. The accompanying ends are drawn from the exploratory outcomes.

- In tensile testing, it is observed that there is an increase in Young's modulus of the composite material for different percentage of nanoparticles.

- The specimen with $2.5 \%$ of nanoparticle $(1.5 \%$ of $\mathrm{SiO}_{2}$ and $1 \%$ of $\mathrm{GO}$ ) composition gives better tensile strength.

From the test results, one can presume that the tensile strength of the composites was controlled effectively by presenting nanoparticles in the framework material. 


\section{References}

1. Jun Feng Hua, Xi Dengb, Teng Zhou Xuc, Zhou Chena, Elsevier, 14 (2019).

2. G.L.Devnania, Shishir Sinha, Materials Today: Proceedings, 18 (2019).

3. Pavan Kumar Gangineni, Sagar Yandrapu, Sohan Kumar Ghosh, Abhijeet Anand, Rajesh Kumar Prusty, Bankim Chandra Ray, Elsevier, 122 (2019).

4. Ramu P, Jaya Kumar CV and Palanikumar K, Materials Today: Proceedings, 1287 (2019).

5. Andrew Makeev, Sarvenaz Ghaffari, Guillaume Seon, International Journal of Engineering Science, (2019).

6. Ramesh Kumar Nayak, Bankim Chandra Ray, Archives of Civil \& Mechanical Engineering, Elsevier, 18, 1597 (2019).

7. Shibo Li, Linquan Zhang, Wenbo Yu, Yang Zhou, International, 43, 6963 (2017).

8. K. P. Ashik, Ramesh S. Sharma, Journal of Minerals and
Materials Characterization and Engineering, 3 (2015).

9. João R. Correia, Marco M. Gomes, José M. Pires, Fernando A. Branco, Composite Structures, Elsevier, 98, 43 (2013).

10. V. Muthukumar, R. Venkatasamy, V. Mariselvam, A. Sureshbabu, N. Senthilkumar4e, A. Antony George Fernando, Applied Mechanics and Materials, 592, 92 (2014).

11. Haider AL-Zubaidya,Xiao-Ling Zhaoa,Riadh AlMihaidi, Procedia Engineering, 10, 2453 (2011).

12. Stephan Sprenger, Journal of Composite Materials, 49 (2013).

13. A. Padma Rao and A. Satyanarayana, Materials Today: Proceedings, (2021).

14. B. Mouhmida, A.Imada, N.Benseddiqa, S.Benmedakhe'neb , A.Maazouzc, Polymer Testing, Elsevier, 25, 544 (2006).

15. R.O. Ochola, K. Marcus, G.N. Nurick, T. Franz, Composite Structures, 63, 455 (2004). 


\section{Appendix:}

\section{Sample calculations to prepare specimen:}

Density of E Glass fibre

$=2.55 \mathrm{gm} / \mathrm{cm}^{3}$

Density of Epoxy LY556 Resin

$=1.20 \mathrm{gm} / \mathrm{cm}^{3}$

Density of HY951 Hardener

$=0.99 \mathrm{gm} / \mathrm{cm}^{3}$

Density of Matrix

$=1.20+0.98 / 2$

$=1.095 \mathrm{gm} / \mathrm{cm}^{3}$

Volume of Composite $(V c)$

$$
=250 \times 25 \times 3
$$$$
=18.75 \mathrm{~cm} 3
$$

The percentage ratio of fibre to matrix should be taken as $60: 40$

Volume of Fibre $(\mathrm{Vf}) \quad=($ weight $\%$ of fibre $) \times(\mathrm{VC}) / 100$

$$
\begin{aligned}
& =(60 \times 18.75) / 100 \\
& =11.25 \mathrm{~cm}^{3}
\end{aligned}
$$

Volume of Resin $(\mathrm{VR}) \quad=($ volume $\%$ of resin $) \times(\mathrm{VC}) / 100$

$$
\begin{aligned}
& =(40 \times 18.75) / 100 \\
& =7.5 \mathrm{~cm}^{3}
\end{aligned}
$$

Weight of Fibre $(W f)=$ Density of Fibre $\mathrm{x}$ Volume of Fibre

$$
\begin{aligned}
& =2.55 \times 11.25 \\
& =28.78 \mathrm{gm}
\end{aligned}
$$

Weight of Matrix $(\mathrm{Wm})=$ Density of Matrix x Volume of Resin

$$
\begin{aligned}
& =1.095 \times 7.5 \\
& =8.128 \mathrm{gm}
\end{aligned}
$$

Specimens without Nanoparticles

For combination of LY556 and HY951:

$$
\begin{array}{ll}
\text { Density of E Glass fiber } & =2.55 \mathrm{gm} / \mathrm{cm}^{3} \\
\text { Density of Epoxy LY556 Resin } & =1.20 \mathrm{gm} / \mathrm{cm}^{3} \\
\text { Density of HY951 Hardener } & =0.99 \mathrm{gm} / \mathrm{cm}^{3} \\
\text { Density of Matrix } & =1.20+0.992 \\
& =1.095 \mathrm{gm} / \mathrm{cm}^{3} \\
\text { Volume of Composite }(\mathrm{Vc}) & =250 \times 25 \times 3 \\
& =18.75 \mathrm{~cm}^{3}
\end{array}
$$

The percentage ratio of fiber to matrix should be taken as 60:40

Volume of Fiber $(\mathrm{Vf}) \quad=($ volume $\%$ of fiber $) \times(\mathrm{VC}) / 100$

$$
\begin{aligned}
& =(60) \times(18.75) / 100 \\
& =11.25 \mathrm{~cm}^{3} \\
\text { Volume of Matrix }(\mathrm{Vm}) & =(\text { volume } \% \text { of matrix }) \times(\mathrm{VC}) \\
& =(40) \times(17.75) / 100
\end{aligned}
$$

$$
=7.5 \mathrm{~cm}^{3}
$$

Weight of Fiber (Wf) = Density of Fiber x Volume of Fiber

$$
=2.55 \times 11.25
$$$$
=28.68 \mathrm{gm}
$$

Weight of Matrix (Wm) = Density of Matrix x Volume of Resin

$$
\begin{aligned}
& =1.095 \times 7.5 \\
& =8.212 \mathrm{gm}
\end{aligned}
$$

Specimens with Nanoparticles

Sample Calculations to prepare specimen:

For Graphene Oxide (GO):

Density of Graphene Oxide $(\rho G O)=1.8 \mathrm{gm} / \mathrm{cm}^{3}$ Density of matrix $(\rho \mathrm{m})$ $=1.095 \mathrm{gm} / \mathrm{cm}^{3}$

Density of modified matrix $(\rho m m)=\left(\rho_{m}+\rho_{G O}\right) / 2$

$$
=1.4475 \mathrm{gm} / \mathrm{cm} 3
$$

Weight of modified matrix $(\mathrm{Wmm})=\rho m m+V m$

$$
\begin{aligned}
& =1.4475 * 7.5 \\
& =10.85 \mathrm{gm}
\end{aligned}
$$

For Silicon dioxide (SiO2)

Density of Silicon dioxide $(\rho \mathrm{SiO} 2)=2.65 \mathrm{gm} / \mathrm{cm} 3$

Weight of modified matrix

$$
\begin{aligned}
& =\rho \mathrm{mm} \times \mathrm{Vm} \\
& =1.8725 \times 7.5 \\
& =14.0437 \mathrm{gm}
\end{aligned}
$$

Preparation of test Specimens with $0.5 \%$ of Nano Particle:

$0.5 \%$ of nanoparticle is the mixture of $0.3 \%$ of $\mathrm{SiO}_{2}$ and $0.2 \%$ of GO $0.3 \%$ of $\mathrm{SiO} 2$ in resin $=(0.3 / 100) \times 14.043$

$\begin{array}{ll} & =0.04212 \mathrm{gm} \\ \text { Resin taken } & =14.043-0.04212 \\ & =14.001 \mathrm{gm} \\ \text { Hardener } & =1 \backslash 10 \mathrm{of} \text { resin } \\ & =1.4043 \mathrm{gm} \\ \text { Hardener taken } & =1.4043-0.0042 \\ \text { Total } \mathrm{SiO}_{2} \text { taken } & =1.4001 \mathrm{gm} \\ 0.2 \% \text { of GO in resin } & =0.04633 \mathrm{gm} \\ & =0.0217 \mathrm{gm} \\ \text { Resin taken } & =10.8283 \mathrm{gm} \\ \text { Hardener } & =1 \backslash 10 \mathrm{of} \text { resin }\end{array}$




$$
=1.085 \mathrm{gm}
$$

$0.2 \%$ of GO in Hardener $=(0.2 / 100) \times 1.085$

$=0.00217 \mathrm{gm}$

Hardener taken $\quad=1.0828 \mathrm{gm}$

Total GO taken $\quad=0.02387 \mathrm{gm}$

Total weight of resin taken $=12.41 \mathrm{gm}$

Total weight of Hardener $=1.241 \mathrm{gm}$ 